\begin{tabular}{|c|l|}
\hline Title & $\begin{array}{l}\text { Evidence of formation of submicrometer water-soluble organic aerosols at a deciduous forest site in northern Japan in } \\
\text { summer }\end{array}$ \\
\hline Author(s) & Miyazaki, Y uzo; Jung, Jinsang; Fu, Pingqing; Mizoguchi, Y asuko; Y amanoi, Katsumi; Kawamura, Kimitaka \\
\hline Citation & $\begin{array}{l}\text { Journal of Geophysical Research, A tmospheres, 117, D19213 } \\
\text { https:/doi.org/10.1029/2012DD018250 }\end{array}$ \\
\hline Issue Date & 2012-10-13 \\
\hline Doc URL & http://hdl.handle.net/2115/52664 \\
\hline Rights & O2012A A merican Geophysical Union. \\
\hline Type & article \\
\hline File Information & JGR117_D19213.pdf \\
\hline
\end{tabular}

Instructions for use 


\title{
Evidence of formation of submicrometer water-soluble organic aerosols at a deciduous forest site in northern Japan in summer
}

\author{
Yuzo Miyazaki, ${ }^{1}$ Jinsang Jung, ${ }^{1,2}$ Pingqing Fu, ${ }^{1,3}$ Yasuko Mizoguchi, ${ }^{4}$ Katsumi Yamanoi, ${ }^{4}$ \\ and Kimitaka Kawamura ${ }^{1}$
}

Received 6 June 2012; revised 7 August 2012; accepted 16 August 2012; published 13 October 2012.

[1] Semicontinuous measurements of submicrometer water-soluble organic aerosols and particle size distributions were conducted at a deciduous forest site in northern Japan in August 2010. Increases in particle number concentration were frequently observed in daytime, accompanied by an increase in the concentrations of water-soluble organic carbon (WSOC). We found that daily averaged WSOC concentrations positively correlated with gross primary production of $\mathrm{CO}_{2}$ by the forest ecosystem $\left(\mathrm{r}^{2}=0.63\right)$ and ambient temperature during daytime. These relations suggest that the formation of WSOC is closely linked to photosynthetic activity by the forest ecosystem, which depends on both temperature and solar radiation. Off-line chemical analysis of samples of particles with aerodynamic diameter smaller than $1 \mu \mathrm{m}$ collected during a 2 day event of elevated WSOC levels suggests that photochemical aging of both $\alpha$ - and $\beta$-pinene and isoprene oxidation products contributes to the particle growth and the WSOC mass. Organic tracers of primary biological aerosol particles (PBAPs) showed distinct diurnal variations with a maximum around noontime, also indicating that higher temperature and light intensity induce emissions of PBAPs. However, their contribution to the submicrometer WSOC mass was likely insignificant. During the day, the concentrations of 3-methyl-1,2,3-butanetricarboxylic acid (3-MBTCA) showed a strong dependence on temperature, and the ratios of WSOC to particle volume concentration increased with an increase in the concentration ratios of 3-MBTCA to pinonic acid (PA). This result supports a previous proposal that the 3-MBTCA/PA ratios in submicrometer particles can be a useful tracer for chemical aging of biogenic secondary organic aerosol from forest vegetation.

Citation: Miyazaki, Y., J. Jung, P. Fu, Y. Mizoguchi, K. Yamanoi, and K. Kawamura (2012), Evidence of formation of submicrometer water-soluble organic aerosols at a deciduous forest site in northern Japan in summer, J. Geophys. Res., 117, D19213, doi:10.1029/2012JD018250.

\section{Introduction}

[2] Biological processes in forest ecosystems largely affect the chemical properties of atmospheric aerosols [e.g., Kavouras et al., 1998; Peñuelas and Staudt, 2010]. For example, photosynthesis by forest vegetation and subsequent emissions of biogenic volatile organic compounds (BVOCs) are important components for the formation of organic

\footnotetext{
${ }^{1}$ Institute of Low Temperature Science, Hokkaido University, Sapporo, Japan.

${ }^{2}$ Now at Korea Research Institute of Standards and Science, Daejeon, South Korea.

${ }^{3}$ Now at Institute of Atmospheric Physics, Chinese Academy of Sciences, Beijing, China.

${ }^{4}$ Hokkaido Research Center, Forestry and Forest Products Research Institute, Sapporo, Japan.

Corresponding author: Yuzo Miyazaki, Institute of Low Temperature Science, Hokkaido University, Kita-19, Nishi-8, Kita-ku, Sapporo 060-0819, Japan. (yuzom@lowtem.hokudai.ac.jp)

C2012. American Geophysical Union. All Rights Reserved. 0148-0227/12/2012JD018250
}

aerosols (OA) in the forest atmosphere [Kulmala et al., 2004; Tunved et al., 2006]. In forests, new particle formation and subsequent growth of particles are linked to the chemical composition of aerosols [e.g., Mäkelä et al., 2001; Kourtchev et al., 2008]. Those aerosol particles typically contain a substantial amount of water-soluble organic carbon (WSOC) in the submicrometer size range [e.g., Cavalli et al., 2006; Hallquist et al., 2009], which can affect the hygroscopic properties and cloud condensation nuclei $(\mathrm{CCN})$ activities of the particles [e.g., Wong et al., 2011]. Although the potential importance of forest aerosols has been recognized in affecting climate change [Pöschl et al., 2010; Mahowald, 2011], chemical properties of submicrometer OA from forest vegetation are poorly represented in global models [Bonan, 2008].

[3] The characterization of WSOC in forests remains challenging because of multiple contributing sources, variable oxidant concentrations and composition, and the variable contributions of background gases and aerosols from regions outside the forests [e.g., De Gouw and Jimenez, 2009]. Understanding the formation processes of WSOC 
and their controlling factors in forests requires extensive field studies, in which significant amounts of biogenic OA are expected to determine clearly the diurnal variations of the biogenic signals. However, studies are still limited in terms of time-resolved variations of submicrometer WSOC both at bulk and molecular levels in the forest atmosphere.

[4] Terpenes, one of the major BVOC precursors of biogenic secondary OA (BSOA), have been linked to increases in ambient aerosol number concentrations in forests [e.g., Tunved et al., 2006]. A recent field study revealed that $\alpha$-pinene oxidation products such as 3-methyl-1,2,3-butanetricarboxylic acid (3-MBTCA) exhibit a strong Arrhenius-type temperature dependence for aerosol samples collected on a weekly basis in Mainz, Germany [Y. Y. Zhang et al., 2010]. A similar temperature dependence of MBTCA, pinic acid, and terebic acid was found in $\mathrm{PM}_{2.5}$ samples collected during daytime ( $\sim 12 \mathrm{~h}$ duration) at a Belgian forest site [Gómez-González et al., 2012]. Based on the temperature dependence, $Y$. $Y$. Zhang et al. [2010] suggested that 3-MBTCA serves as a suitable tracer for the aging of BSOA by the hydroxyl radicals $(\mathrm{OH})$. Field studies with time-resolved measurements are essential for assessing the temperature dependence on BSOA formation [e.g., Leaitch et al., 2011]. Besides BSOA, the contribution of primary biological aerosol particles (PBAPs) such as spores and bacteria to submicrometer WSOC is poorly understood in forests.

[5] In our previous study [Miyazaki et al., 2012], we measured stable carbon isotope ratios of WSOC and biogenic tracer compounds in total suspended particulate matter (TSP) collected on a weekly basis for 18 months at a deciduous forest site in northern Japan. The study suggested that the production of both primary and secondary OA had similar contributions to the WSOC mass during the growing season (early summer), whereas the formation of WSOC in midsummer is mainly driven by the oxidation of monoterpenes and isoprene. Here we characterize the temporal variations in submicrometer WSOC and particle growth on a shorter timescale of hours to days, based on intensive online measurements of WSOC and particle size distributions at the same forest site in the summer of 2010. We also present the analytical results for biogenic SOA tracers and organic tracers of PBAPs in $\mathrm{PM}_{1.0}$ during a 2 day event of elevated WSOC concentrations, and discuss the temperature dependence of biogenic WSOC during daytime.

\section{Experiments}

\subsection{Site Description}

[6] Aerosol measurements were made on a flux tower at the Sapporo forest meteorology research site $\left(42^{\circ} 59^{\prime} \mathrm{N}, 141^{\circ} 23^{\prime} \mathrm{E}\right.$, $182 \mathrm{~m}$ above sea level) located in the western part of Hokkaido, the northernmost major island of Japan [Kitamura et al., 2012; Miyazaki et al., 2012]. The experimental site is a secondary forest which is covered with broadleaf deciduous trees dominated by white birch (Betula platyphylla) and Mizunara oak (Quercus crispula). The surrounding area is covered with needleleaf evergreen trees. The forest floor is widely covered with evergreen Sasa bamboo (Sasa senanensis and Sasa kurilensis). The foliation stage in the forest starts at the end of April through the beginning of May, and the foliated period lasts until the end of September [Kitamura et al., 2012]. The seasonal variation of the leaf area index
(LAI) of this forest is similar to those of typical temperate deciduous forests [Nakai et al., 2003]. The predominant wind direction at the forest site in summer and autumn (MayOctober) suggests that the majority of the air masses passed over the forested area [see Miyazaki et al., 2012, Figure 1].

\subsection{Aerosol Measurements}

\subsubsection{Online Measurement Methods}

[7] Submicrometer particles were sampled by a suite of colocated online instruments for measuring WSOC concentration and particle size distribution on 10-19 August and 25-27 August 2010. A measurement strategy was designed to investigate the chemical characteristics of WSOC in submicrometer particles associated with forest biological activity. Ambient aerosols were sampled $\sim 15 \mathrm{~m}$ above the forest floor through a $\mathrm{PM}_{1}$ cyclone inlet mounted on the tower at a flow rate of $16.7 \mathrm{~L} \mathrm{~min}^{-1}$. WSOC was quantified using a particle-into-liquid sampler (PILS) coupled to a total organic carbon (TOC) analyzer (Model 810; Sievers, Boulder, CO) [Sullivan et al., 2004; Miyazaki et al., 2006], which was placed inside a shelter at the bottom of the tower. The details of the instrument are given elsewhere [Miyazaki et al., 2006]. Briefly, particles smaller than $1 \mu \mathrm{m}$ in diameter were passed through an organic carbon denuder to remove organic vapors and sampled by the PILS. Particles were grown inside the PILS chamber into droplets, which were collected by inertial impaction in the PILS. The samples were dissolved into Milli-Q water and then filtered with a disc filter (Millex-GV, $0.22 \mu \mathrm{m}$, Millipore, Billerica, Massachusetts, USA), followed by injection into a TOC analyzer for quantification of WSOC. The data was obtained every $6 \mathrm{~min}$. The reported WSOC levels are the difference between the measured and background concentrations. The overall uncertainty of the measurement is estimated at approximately $10 \%$ with a lower detection limit of $0.1 \mu \mathrm{g} \mathrm{C} \mathrm{m}^{-3}$.

[8] A scanning mobility particle sizer (SMPS) was deployed to measure the particle size distribution, which consists of a differential mobility analyzer (DMA; TSI Model 3081) coupled to a condensation particle counter (CPC; TSI Model 3775). From another inlet located close to the PILS inlet, ambient aerosols were also sampled through a $\mathrm{PM}_{1}$ cyclone inlet at a flow rate of $16.7 \mathrm{~L} \mathrm{~min}^{-1}$. An aliquot $\left(0.3 \mathrm{~L} \mathrm{~min}^{-1}\right)$ of the sampled air was separated and dried to a relative humidity $<5 \%$ using two diffusion dryers before being introduced into the SMPS. A logarithmic scan from a mobility diameter of $14 \mathrm{~nm}$ to $750 \mathrm{~nm}$ was completed every 5 min. Flow rates of sample and sheath air in the DMA were set at 0.3 and $3.0 \mathrm{~L} \mathrm{~min}^{-1}$, respectively, to give a 10:1 flow rate ratio of sheath to aerosol. In the current analysis, when the SMPS and PILS-WSOC data are merged, $30 \mathrm{~min}$ averaged WSOC and particle volume concentrations are available.

\subsubsection{P.M $\mathbf{M}_{1.0}$ Aerosol Filter Samplings and Off-Line Chemical Analysis}

[9] In order to evaluate the diurnal variations of WSOC, a four-stage cascade impactor (Series 230, Tisch Environmental, Cleves, Ohio, USA) attached to a high-volume air sampler was employed to collect particles. The air sampler was placed at an altitude $\sim 15 \mathrm{~m}$ above the forest floor (just below the canopy height) at the research site. In the current study, we only used analytical results obtained from the bottom stage of the impactor, which collected particles with aerodynamic diameter smaller than $1 \mu \mathrm{m}\left(\mathrm{PM}_{1.0}\right)$. On 25 
27 August 2010, $\mathrm{PM}_{1.0}$ sampling was conducted using precombusted (at $450^{\circ} \mathrm{C}$ for at least $6 \mathrm{~h}$ ) quartz fiber filters $(25 \times 20 \mathrm{~cm})$ at a flow rate of $1,130 \mathrm{~L} \mathrm{~min}^{-1}$. The sample collection was performed with collection intervals of $3 \mathrm{~h}$ during daytime (06:00-18:00 LT) and $12 \mathrm{~h}$ at night (18:0006:00 LT), which resulted in the collection of 5 samples per day. The sampling yielded collected air volumes of $\sim 200 \mathrm{~m}^{3}$ and $\sim 820 \mathrm{~m}^{3}$ during the day and at night, respectively.

[10] To determine the WSOC concentrations in the $\mathrm{PM}_{1.0}$ samples, a filter portion of $\sim 14 \mathrm{~cm}^{2}$ was extracted with $10 \mathrm{ml}$ of ultrapure Milli-Q water using an ultrasonic bath for $15 \mathrm{~min}$. The extracts were then filtered with the same type of disc filter as used for the PILS-WSOC, followed by injection of the extracts into a total organic carbon analyzer (Model TOCVcsh, Shimadzu, Kyoto, Japan) [Miyazaki et al., 2011]. A detection limit for this filter-based measurement of WSOC was estimated to be $\sim 0.09 \mu \mathrm{g} \mathrm{C} \mathrm{m}^{-3}$. Online measurements of WSOC with the PILS-TOC were compared to filter-based off-line measurements of WSOC on 25 August. The results revealed that, although nondenuded integrated filter measurements were approximately $13 \%$ higher than those obtained for denuded online WSOC, the data obtained by the two methods were highly correlated (linear regression $\mathrm{r}^{2}$ of 0.74 ). Slightly lower WSOC values obtained by the PILS measurements can be explained by several factors, including sampling artifacts associated with each measurement (e.g., adsorption of volatile organic compounds that contributed to the particle sampling), and differences in the solubility of various organic compounds. Similar differences between the two methods have been reported previously [Miyazaki et al., 2006; Sullivan et al., 2006].

[11] For the analysis of biogenic tracer compounds, a filter portion was extracted with dichloromethane/methanol [Fu et al., 2009]. The $-\mathrm{COOH}$ and $-\mathrm{OH}$ functional groups in the extracts were reacted with N,O-bis-(trimethylsilyl) trifluoroacetamide (BSTFA) to form TMS esters and TMS ethers, respectively. The TMS derivatives were then analyzed for the above compounds using a capillary gas chromatograph (HP GC6890, Hewlett-Packard, Palo Alto, California, USA) coupled to a mass spectrometer (5973 MSD, Agilent, Santa Clara, California, USA) [Fu et al., 2009]. We measured 3-methyl-1,2,3-butanetricarboxylic acid (3-MBTCA), 3-hydroxyglutaric acid (3-HGA), pinic acid, and pinonic acid as BSOA tracers for $\alpha$ - and $\beta$-pinene [Yu et al., 1999; Claeys et al., 2007; Szmigielski et al., 2007]. As isopreneSOA tracers, we determined the concentrations of the two diastereoisomeric 2-methyltetrols (2-methylerythritol and 2-methylthreitol) [Claeys et al., 2004]. In addition, we quantified sucrose, trehalose, arabitol, and mannitol as possible tracers for PBAPs [Simoneit et al., 2004; Elbert et al., 2007]. The measurements of the biogenic tracer compounds discussed here had lower detection limits of $<0.002 \mathrm{ng} \mathrm{m}^{-3}$.

[12] For determination of inorganic ions, another filter portion was extracted with $10 \mathrm{ml}$ of Milli-Q water. The extract was filtered through a membrane disc filter, and major ions including sulfate and nitrate were determined using a Metrohm ion chromatograph (Model 761 compact IC; Metrohm, Herisau, Switzerland) [Miyazaki et al., 2012]. The sulfate and nitrate measurements had detection limits of 0.04 and $0.05 \mu \mathrm{g} \mathrm{m}^{-3}$, respectively. Mass concentrations of elemental carbon (EC) were measured using a Sunset Lab carbon analyzer (Sunset Laboratory, Inc., Tigard, Oregon, USA). In the present study, we used a temperature protocol based on that proposed by the National Institute for Occupational Safety and Health (NIOSH) [Birch and Cary, 1996]. A lower detection limit for EC was estimated to be $\sim 0.08 \mu \mathrm{g} \mathrm{C} \mathrm{m}^{-3}$.

\section{3. $\mathrm{CO}_{2}$ Flux and Meteorological Parameters}

[13] The net $\mathrm{CO}_{2}$ exchange between the forest ecosystem and the atmosphere (net ecosystem exchange, NEE) was obtained to characterize the aerosol carbon dynamics in terms of forest photosynthetic activity. NEE is determined as the sum of the $\mathrm{CO}_{2}$ eddy covariance flux and the change in $\mathrm{CO}_{2}$ storage below the eddy measurement level $(28.5 \mathrm{~m})$ [Nakai et al., 2003; Kitamura et al., 2012]. The eddy covariance fluxes of $\mathrm{CO}_{2}$ were measured in the flux tower using a three-dimensional (3-D) ultrasonic anemothermometer (DA600-3T, Sonic), a closed-path infrared $\mathrm{CO}_{2} / \mathrm{H}_{2} \mathrm{O}$ gas analyzer (IRGA) (Li6262, LiCor), a thermo hygrometer (HMP45A, Vaisala), and a pressure gauge (PTB210, Vaisala). To quantify the storage of $\mathrm{CO}_{2}$ below the altitude level of the eddy measurement, vertical profiles of $\mathrm{CO}_{2}$ concentration were obtained from air samples taken at five heights [Kitamura et al., 2012]. The sample air was collected via sampling inlets mounted on the tower and was pumped through PTFE tubes to the IRGA inside the shelter on the ground.

[14] In the present study, an upward $\mathrm{CO}_{2}$ flux is assigned to be positive, which means that a negative NEE value indicates net uptake of $\mathrm{CO}_{2}$ by the forest ecosystem. Further details of the NEE derived here have been described previously [Kitamura et al., 2012]. Miyazaki et al. [2012] demonstrated that the seasonal cycle of stable carbon isotopic composition of WSOC $\left(\delta^{13} \mathrm{C}_{\mathrm{WSOC}}\right)$ in total suspended particulate matter (TSP) corresponds to that of NEE at the same forest site, indicating that WSOC in TSP is primarily influenced by biological activity at this forest site in summer.

[15] In addition to the NEE, the gross primary production (GPP) was derived, which is the amount of $\mathrm{CO}_{2}$ assimilated by photosynthesis. The GPP can be defined as the balance between the NEE and the total ecosystem respiration (RE):

$$
\mathrm{GPP}=-\mathrm{NEE}+\mathrm{RE}
$$

[16] An empirical model of total dark respiration was established by adjusting the nighttime and leaf-off values of NEE [e.g., Wofsy et al., 1993] to a relevant temperature and extrapolating this model to the daytime respiration [Nakai et al., 2003; Kitamura et al., 2012].

[17] Local meteorological parameters were measured every 10 min by a weather transmitter (WXT-510, Vaisala, Finland) at a point close to the aerosol inlets. The average ambient temperature and relative humidity $(\mathrm{RH})$ were $22.0 \pm 2.8^{\circ} \mathrm{C}$ and $85.5 \pm 10.1 \%$, respectively, during the study period. Ozone $\left(\mathrm{O}_{3}\right)$ was measured using the UV absorption technique with an integration time of 1 min (Model 1101; Dylec, Tokyo).

\section{Results and Discussion}

\subsection{Time Series of WSOC and Particle Number Size Distributions}

[18] Figure 1a shows a time series of the WSOC and particle volume concentrations over a 9 day period (10-18 August). The WSOC concentrations ranged from levels below the detection limit to a maximum value of $\sim 2 \mu \mathrm{g} \mathrm{C} \mathrm{m}^{-3}$, with an 


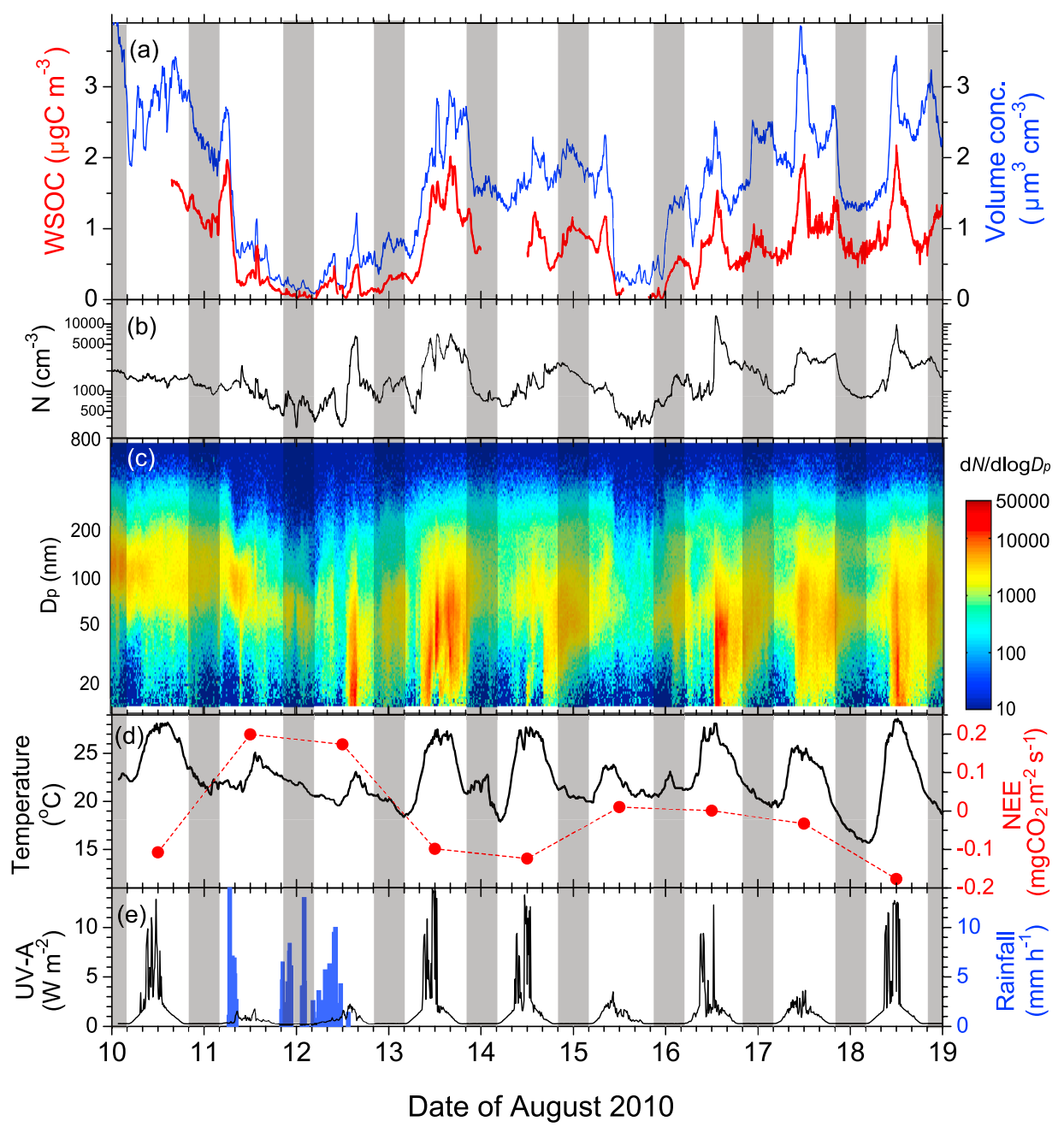

Figure 1. Temporal variations of (a) WSOC and total volume concentrations in the submicrometer range, (b) particle number concentrations $(\mathrm{N})$, (c) size distribution of $\mathrm{N}$, (d) ambient temperature and NEE, and (e) UVA intensity and rainfall during the period of 10-18 August 2010. Shaded areas indicate nighttime.

average of $0.83 \pm 0.45 \mu \mathrm{g} \mathrm{C} \mathrm{m}^{-3}$ during the entire period. The peaks of the WSOC concentrations were typically observed around noon or in the afternoon (e.g., 13, 16-18 August). The temporal variation in the WSOC concentrations closely follows those of the particle volume concentrations $\left(r^{2}=0.81\right)$ and number concentrations $\left(\mathrm{r}^{2}=0.45\right)$ (Figures $1 \mathrm{a}$ and $1 \mathrm{~b}$ ). The average ratio of WSOC to particle volume concentration (Figure 2) during the entire period was $0.44 \pm 0.14 \mu \mathrm{g} \mathrm{C} \mathrm{m}^{-3}$ / $\left(\mu \mathrm{m}^{3} \mathrm{~cm}^{-3}\right)$, which is much higher than those $(0.10$ $\left.0.30 \mu \mathrm{g} \mathrm{C} \mathrm{m}^{-3} /\left(\mu \mathrm{m}^{3} \mathrm{~cm}^{-3}\right)\right)$ observed for urban and biomass burning plumes in the United States [Peltier et al., 2007; Duong et al., 2011]. These results suggest that the forest site provides substantial sources of water-soluble organics in the submicrometer particles.

[19] Particle number concentrations ranged from 270 to $13,230 \mathrm{~cm}^{-3}$, with an average of $1776 \pm 1367 \mathrm{~cm}^{-3}$. A distinct increase in the number concentrations $\left(>2000 \mathrm{~cm}^{-3}\right)$ of the particles in a size range of $20-200 \mathrm{~nm}$ was observed mostly around noon or in the afternoon (Figures $1 \mathrm{~b}$ and $1 \mathrm{c}$ ). These events include new particle formation and subsequent particle growth (Figure 1c), accompanied by a simultaneous increase in WSOC concentrations. The increase was associated with increased ambient temperature (up to $28^{\circ} \mathrm{C}$ ) and UV light intensity (Figures 1d and 1e). Diurnal variations in the ratios of WSOC to particle volume concentration showed a peak at 12:00-15:00 LT $\left(\sim 0.52 \pm 0.16 \mu \mathrm{g} \mathrm{C} \mathrm{m}^{-3} /\right.$ $\left(\mu \mathrm{m}^{3} \mathrm{~cm}^{-3}\right)$ ), and a decrease in the evening (Figure 2a). An increase in the ratio of WSOC to particle volume concentration was typically observed when the air masses were transported from the forested area extending to the south of the sampling location by southerly winds (Figure $2 b$ ). Moreover, the meteorological data show that $\sim 70 \%$ of the local wind speed was $<0.5 \mathrm{~m} \mathrm{~s}^{-1}$, indicating that the majority of aerosol sampled during this period was influenced by local biogenic emissions from the forest ecosystem. Therefore, the increase in the ratio of WSOC to particle volume concentration could result from either primary emissions or secondary formation of WSOC. We investigate the sources and chemical composition of WSOC in $\mathrm{PM}_{1.0}$ using filter-based analysis in section 3.4 . 

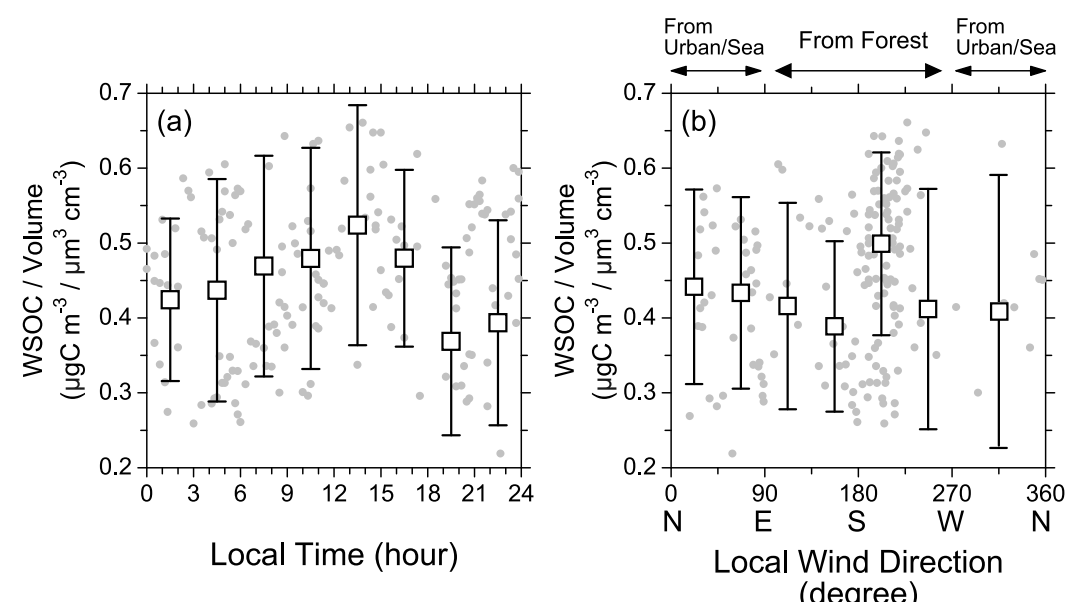

Figure 2. (a) Diurnal variation of WSOC to particle volume concentration ratios in the submicrometer range. Open squares and bars indicate the average values with standard deviations in each $3 \mathrm{~h}$ period. (b) WSOC to particle volume concentration ratios as a function of local wind direction at the forest site. Open squares and bars indicate the average values with standard deviations. Also shown above the top axis are major source regions corresponding to each upwind direction. Data with local wind speed $>0.5 \mathrm{~m} \mathrm{~s}^{-1}$ and particle volume concentration $>0.2 \mu \mathrm{m}^{3} \mathrm{~cm}^{-3}$ are shown.

\subsection{Association of WSOC With $\mathrm{CO}_{2}$ Flux}

[20] In general, the daily averaged NEE was negatively correlated with WSOC concentrations (Figure 1d). Figure 3 shows the $24 \mathrm{~h}$ averaged WSOC concentrations as functions of the NEE and the gross primary production (GPP). To our knowledge, this is the first study to show a linkage of the submicrometer WSOC with NEE and GPP on a daily timescale. The $r^{2}$ between WSOC concentrations and NEE is 0.57 on a daily basis (Figure 3a). Additionally, the WSOC levels positively correlate with GPP $\left(\mathrm{r}^{2}=0.63\right)$. These correlations suggest that the origin of WSOC in the submicrometer aerosols at the study site is closely linked to the photosynthetic activity of the forest ecosystem. This supports our previous study [Miyazaki et al., 2012], which reported that the stable isotopic composition of WSOC $\left(\delta^{13} \mathrm{C}_{\mathrm{WSOC}}\right)$ in TSP at the same forest site in summer and autumn exhibited values $(-25.5 \pm 0.5 \%$ o similar to those of $\mathrm{C} 3$ plants. That study indicated that the dominant source of WSOC in TSP is linked with biological activity of local vegetation, mainly related with $\mathrm{C} 3$ plants.

[21] From 11 to 12 August, low values of particle volume concentrations $\left(<1.1 \mu \mathrm{m}^{3} \mathrm{~cm}^{-3}\right)$ and WSOC $\left(<0.8 \mu \mathrm{g} \mathrm{C} \mathrm{m}^{-3}\right)$ were observed, which corresponded to positive values of NEE and rainfall events (Figures $1 \mathrm{~d}$ and 1e). This finding can be explained by wet removal of particles and low biological activity at the forest site. (a)

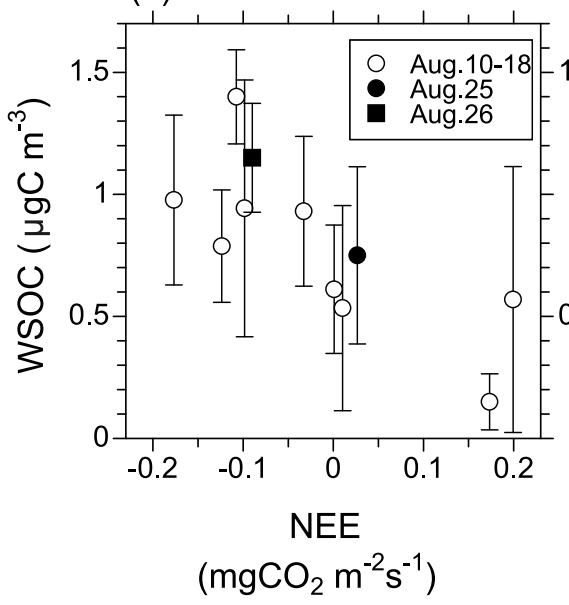

(b)

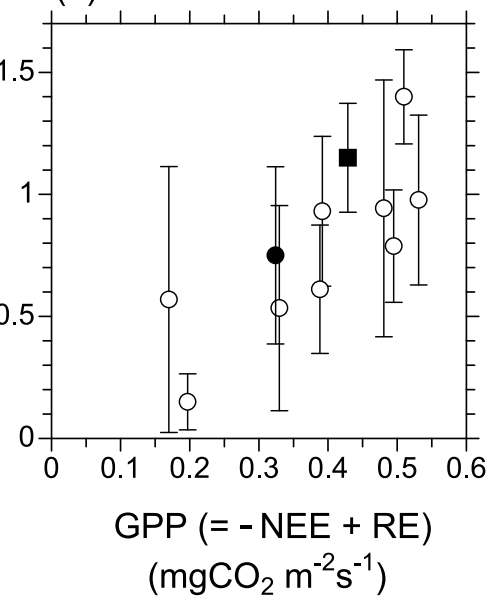

Figure 3. WSOC concentrations ( $24 \mathrm{~h}$ average) as functions of the daily averaged (a) net $\mathrm{CO}_{2}$ exchange between the forest ecosystem and the atmosphere (NEE) and (b) gross primary production (GPP). Open circles indicate data obtained during 10-18 August, and solid circles and squares indicate data obtained on 25 and 26 August, respectively. 

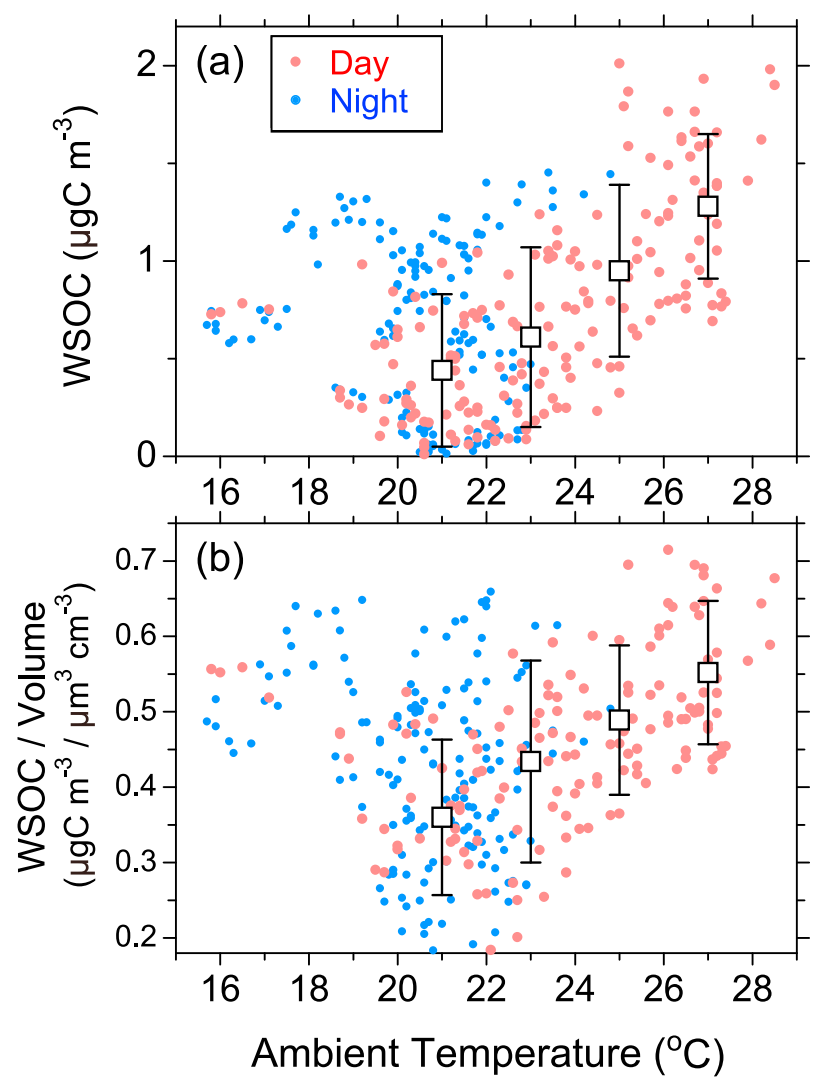

Figure 4. (a) WSOC and (b) concentration ratios of WSOC to particle volume as a function of ambient temperature in daytime (red circles) and nighttime (blue circles). Open squares and bars indicate average values and standard deviations, respectively, for each $2^{\circ} \mathrm{C}$ increment. Average values are not calculated for temperatures $<20^{\circ} \mathrm{C}$ because the number of data points is limited in this range.

\subsection{Temperature Dependence of WSOC}

[22] Figure 4 presents the WSOC concentrations as functions of ambient temperature during daytime (06:00-18:00LT) and nighttime (18:00-06:00LT) during the entire period. To obtain more insight into the importance of temperature dependence of WSOC, the ratios of WSOC to the particle volume concentrations are also plotted against the ambient temperature. During the daytime, both WSOC and the WSOC/ volume concentration ratios increased with increasing ambient temperature in a range of $20.0-28.5^{\circ} \mathrm{C}$. This remarkable dependency on temperature indicates that WSOC was associated mainly with the photosynthetic activities of plants (emission of BVOCs and particles) and subsequent photochemical processes (SOA formation) in the atmosphere during the day. In contrast, such dependence was not observed during the nighttime. The WSOC concentrations and the ratios of WSOC to the particle volume concentrations are rather scattered at night. This result can be partly explained by the trapping of WSOC beneath the canopy, which is significant mainly at night [e.g., Holzinger et al., 2005]. The temperature dependence of biogenic tracers in the submicrometer WSOC aerosols is investigated in section 3.4.5.

\subsection{A Case Study on 25 and 26 August}

[23] To characterize submicrometer WSOC at the forest site, we examined the data sets from two distinct days with different photochemical conditions in the ambient atmosphere. On both 25 and 26 August, temperatures ranged from 17 to $25^{\circ} \mathrm{C}$ (Figure 5a), with averages of $21.2 \pm 2.3$ and $20.1 \pm 2.7^{\circ} \mathrm{C}$, respectively. As shown in Figure 5, the UVA intensity and the peak $\mathrm{O}_{3}$ concentration ( $46 \mathrm{ppbv}$ ) were much higher on 26 August, indicating that the photochemical activity in ambient air was higher than on the previous day. In addition, absolute values of NEE (i.e., net uptake of $\mathrm{CO}_{2}$ ) and GPP were higher on 26 August than on 25 August, as shown in Figure 3. This difference in the averaged NEE and GPP values indicates that the photosynthetic activity of the forest ecosystem was also higher on 26 August. For simplicity, the daytimes of 25 and 26 August are denoted as D1 and D2, respectively, in Figure 5 and the discussion below.

\subsubsection{Diurnal Variations of $\mathbf{P M}_{1.0}$ WSOC}

[24] Figure 6 presents the temporal variations of WSOC concentrations, the ratios of WSOC to particle volume concentrations, particle number size distributions, and biogenic tracer compounds in $\mathrm{PM}_{1.0}$ obtained by filter-based measurements from 25 to 27 August. Averages of the measured parameters are summarized in Table 1. Both WSOC and WSOC/volume concentration ratios increased during daytime and declined at night during the 2 day period (Figure 6a). This pattern of diurnal change is similar to the average profile of the $\mathrm{WSOC} /$ volume concentration ratios obtained by the online methods as shown in Figure 2a. The increase in WSOC and WSOC/volume concentration ratios during daytime was accompanied by particle growth, particularly for D2 (Figure 6b). A doubling of the WSOC concentrations from sunrise to the afternoon, and a decline from the late afternoon to nighttime, suggest photosynthetically initiated emissions of precursors and photochemically

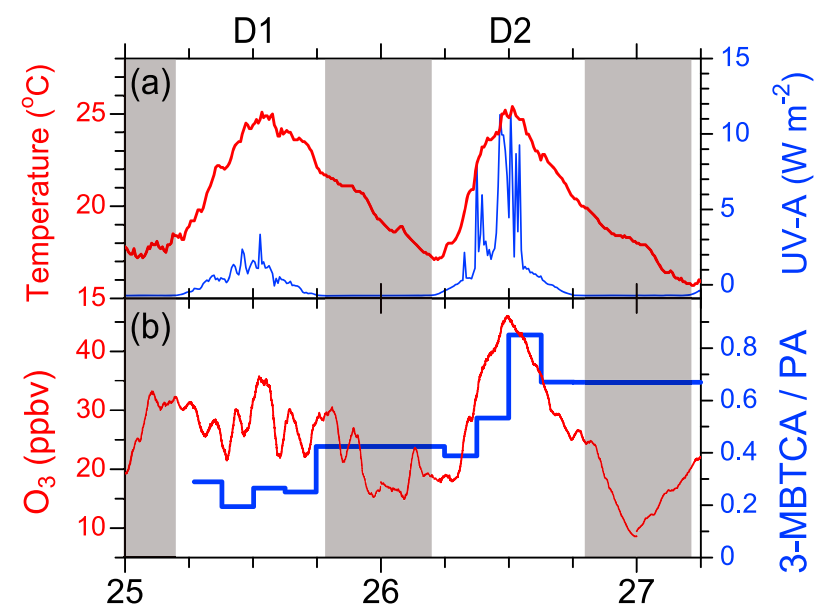

\section{Date of August 2010}

Figure 5. Diurnal variations of (a) ambient temperature (red) and UVA intensity (blue line) and (b) $\mathrm{O}_{3}$ (red line) and the concentration ratios of 3-MBTCA to pinonic acid (PA; blue) from 25 to 27 August 2010. Shaded areas indicate nighttime. 


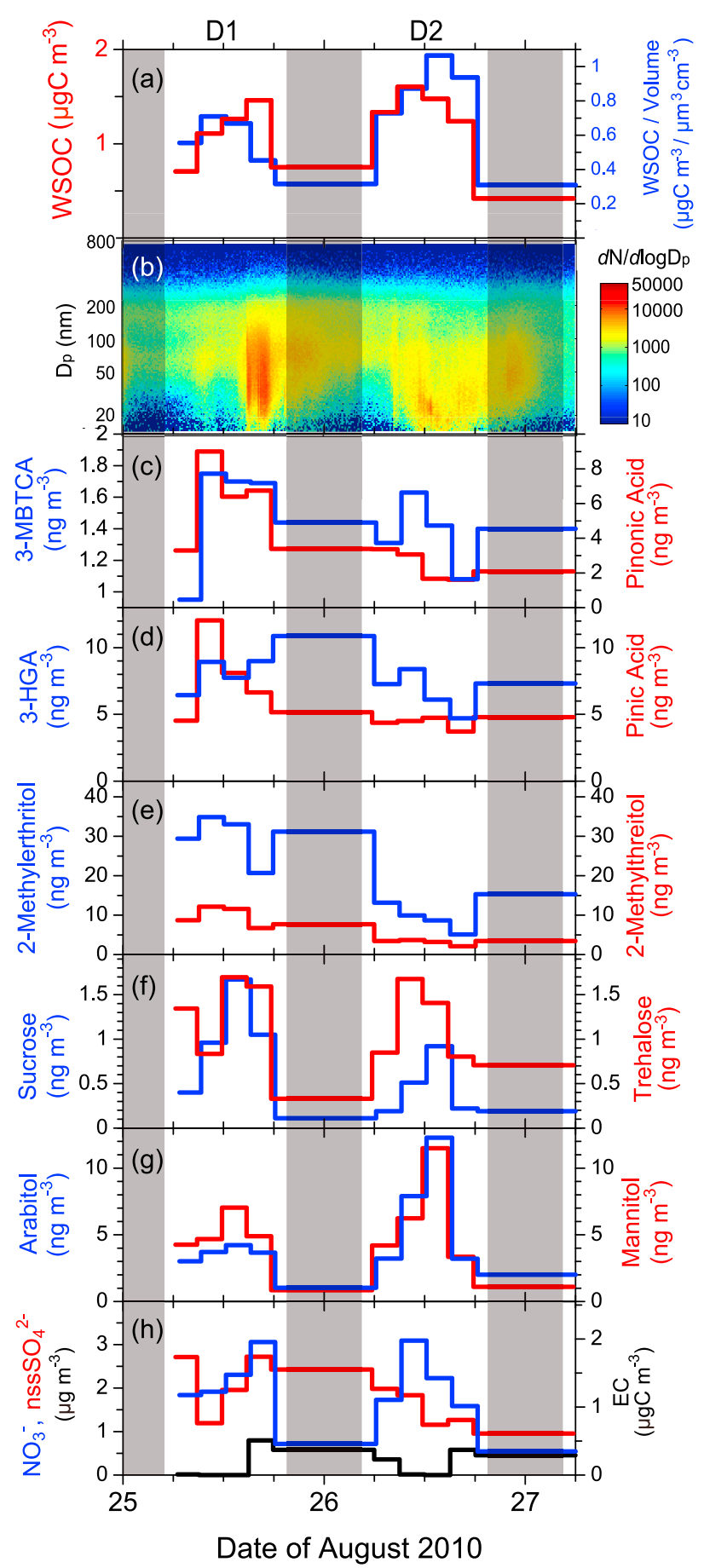

Figure 6. Diurnal variations of (a) WSOC and WSOC/ volume, (b) number size distributions, (c) 3-MBTCA and pinonic acid, (d) 3-HGA and pinic acid, (e) 2-methylerthritol and 2-methylthreitol, (f) sucrose and trehalose, (g) arabitol and mannitol, and (h) nitrate, nss sulfate, and EC in $\mathrm{PM}_{1.0}$ from 25 to 27 August 2010. Shaded areas indicate nighttime.

enhanced WSOC production. Moreover, the average WSOC concentration on $\mathrm{D} 2\left(1.4 \pm 0.2 \mu \mathrm{g} \mathrm{C} \mathrm{m}^{-3}\right)$ was higher than that on $\mathrm{D} 1\left(1.1 \pm 0.3 \mu \mathrm{g} \mathrm{C} \mathrm{m}^{-3}\right)$. Similarly, the average ratio of WSOC to volume concentration on D2 $(0.88 \pm 0.17)$ was much higher than that on $\mathrm{D} 1(0.58 \pm 0.29)$. The elevated WSOC and higher ratio to volume concentrations, which are accompanied by particle growth, indicate that WSOC formed under clear sky conditions is significant at the forest site.

\subsubsection{Biogenic SOA Tracers in $\mathbf{P M}_{1.0}$}

[25] Among the measured $\alpha$ - and $\beta$-pinene SOA tracers, 3 -HGA and pinic acid were the most abundant in $\mathrm{PM}_{1.0}$ aerosols, with average concentrations of $8.2 \pm 1.7 \mathrm{ng} \mathrm{m}^{-3}$ and $5.9 \pm 2.5 \mathrm{ng} \mathrm{m}^{-3}$, respectively. These values are close to the average concentrations in TSP during the entire summer of 2010 (3-HGA: $8.7 \pm 2.8 \mathrm{ng} \mathrm{m}^{-3}$; pinic acid: $4.0 \pm 1.0 \mathrm{ng} \mathrm{m}^{-3}$ ) that were obtained in our previous study [Miyazaki et al., 2012]. This indicates that $\alpha$ - and $\beta$-pinene SOA mostly resides in the submicrometer size range. Kourtchev et al. [2009] also reported that 3-HGA had the highest concentrations (with a median value of $16.8 \mathrm{ng} \mathrm{m}^{-3}$ ) among the $\alpha$ - and $\beta$-pinene SOA tracers in $\mathrm{PM}_{2.5}$ aerosols collected at a mixed coniferous/deciduous forest site in $\mathrm{K}$ puszta, Hungary, during the summer of 2003.

[26] Pinonic and pinic acids are produced by the photooxidation and ozonolysis of $\alpha$ - and $\beta$-pinene via reactions with $\mathrm{OH}$ radicals and $\mathrm{O}_{3}$ [e.g., $\mathrm{Yu}$ et al., 1999]. The reaction rate coefficients $k(\mathrm{OH})$ for $\alpha$-pinene $\left(5.3 \times 10^{-11} \mathrm{~cm}^{3} \mathrm{~s}^{-1}\right)$ and $\beta$-pinene $\left(7.9 \times 10^{-11} \mathrm{~cm}^{3} \mathrm{~s}^{-1}\right)$ [Atkinson et al., 2006] result in $\mathrm{OH}$ lifetimes of $\sim 5 \mathrm{~h}$ for $\alpha$-pinene and $\sim 3.5 \mathrm{~h}$ for $\beta$-pinene, respectively, using a typical average $\mathrm{OH}$ concentration of $1 \times 10^{6} \mathrm{~cm}^{-3}$. Further reaction of the initial oxidation products of pinene leads to highly oxidized, acyclic, polar compounds such as 3-HGA and 3-MBTCA [Szmigielski et al., 2007; Kourtchev et al., 2009; Müller et al., 2012]. The elevated concentrations of pinonic acid $\left(6.4 \mathrm{ng} \mathrm{m}^{-3}\right)$ and pinic $\operatorname{acid}\left(7.8 \mathrm{ng} \mathrm{m}^{-3}\right)$ on D1 rather than on D2 (Figures $6 \mathrm{c}$ and $6 \mathrm{~d}$ ) suggest that photooxidation of $\alpha$ - and $\beta$-pinene oxidation products was less complete, probably due to a relatively weaker photochemical activity on D1 compared to D2. These first-generation products of $\alpha$ - and $\beta$-pinene are further oxidized to higher-generation oxidation products through $\mathrm{OH}$ radical-initiated reactions.

[27] The 3-MBTCA concentrations reached a maximum around noontime; this temporal variation closely follows that of WSOC $\left(r^{2}=0.52\right)$. Additionally, the temporal variation of 3 -HGA is similar to that of 3-MBTCA. These observations indicate that photooxidation of $\alpha$ - and $\beta$-pinene significantly contributed to the submicrometer WSOC. This is supported by our previous study [Miyazaki et al., 2012], in which we used a positive matrix factorization (PMF) method to estimate that $\alpha$ - and $\beta$-pinene SOA accounted for $\sim 50 \%$ of WSOC in TSP at the same forest site in July and August 2010. Besides pinonic and pinic acid, there are other important first-generation $\alpha$-pinene-SOA products, such as lactonecontaining terpenoic acid and terpenylic acid [Claeys et al., 2009], which may also contribute to the WSOC mass but are not detected by the GC/MS method employed in the current study.

[28] Average $\mathrm{PM}_{1.0}$ concentrations of isoprene-SOA tracers, 2-methylerythritol and 2-methylthreitol, were $20.1 \pm$ $11.2 \mathrm{ng} \mathrm{m}^{3}$ and $6.3 \pm 3.7 \mathrm{ng} \mathrm{m}^{-3}$, respectively. These values are also similar to the average concentrations obtained for TSP (2-methylerythritol: $24.8 \pm 14.1 \mathrm{ng} \mathrm{m}^{-3}$; 2-methylthreitol: $6.7 \pm 3.1 \mathrm{ng} \mathrm{m}^{-3}$ ) at the same site in July and August 2010 [Miyazaki et al., 2012]. We did not observe any clear diurnal 
Table 1. Averages of the Measured Parameters on 25 and 26 August 2010

\begin{tabular}{|c|c|c|c|c|}
\hline & \multicolumn{2}{|c|}{25 August } & \multicolumn{2}{|c|}{26 August } \\
\hline & $\begin{array}{c}\text { Daytime (D1) } \\
(06: 00-18: 00 \text { LT) }\end{array}$ & $\begin{array}{c}\text { Nighttime } \\
(18: 00-06: 00 \text { LT) }\end{array}$ & $\begin{array}{c}\text { Daytime (D2) } \\
(06: 00-18: 00 \text { LT) }\end{array}$ & $\begin{array}{c}\text { Nighttime } \\
(18: 00-06: 00 \text { LT })\end{array}$ \\
\hline WSOC $\left(\mu \mathrm{g} \mathrm{C} \mathrm{m}^{-3}\right)$ & $1.14 \pm 0.32$ & 0.75 & $1.41 \pm 0.16$ & 0.42 \\
\hline Particle volume concentrations $\left(\mu \mathrm{m}^{3} \mathrm{~cm}^{-3}\right)$ & $1.96 \pm 0.79$ & $2.28 \pm 0.16$ & $1.60 \pm 0.26$ & $1.35 \pm 0.20$ \\
\hline Ratios of WSOC to particle volume concentrations & $0.58 \pm 0.29$ & $0.33 \pm 0.02$ & $0.88 \pm 0.17$ & $0.31 \pm 0.05$ \\
\hline Particle number concentrations $\left(\mathrm{cm}^{-3}\right)$ & $2316 \pm 2098$ & $1726 \pm 553$ & $1965 \pm 375$ & $1424 \pm 618$ \\
\hline \multicolumn{5}{|l|}{$\alpha$ - and $\beta$-Pinene SOA tracers ${ }^{\mathrm{a}}\left(\mathrm{ng} \mathrm{m}^{-3}\right)$} \\
\hline 3-МBТCA & $1.5 \pm 0.4$ & 1.4 & $1.4 \pm 0.2$ & 1.4 \\
\hline 3-HGA & $8.0 \pm 1.1$ & 10.9 & $6.6 \pm 1.5$ & 7.3 \\
\hline Pinonic acid & $6.4 \pm 2.2$ & 3.4 & $2.4 \pm 0.9$ & 2.1 \\
\hline Pinic acid & $7.8 \pm 2.9$ & 5.2 & $4.3 \pm 0.4$ & 4.8 \\
\hline \multicolumn{5}{|l|}{ Isoprene SOA tracers $\left(\mathrm{ng} \mathrm{m}^{-3}\right)$} \\
\hline 2-Methylthreitol & $9.8 \pm 2.3$ & 7.7 & $3.1 \pm 0.6$ & 3.5 \\
\hline 2-Methylerythritol & $29.5 \pm 5.8$ & 31.2 & $9.2 \pm 3.1$ & 15.3 \\
\hline \multicolumn{5}{|l|}{ PBAP tracers $\left(\mathrm{ng} \mathrm{m}^{-3}\right)$} \\
\hline Sucrose & $1.0 \pm 0.5$ & 0.1 & $0.5 \pm 0.3$ & 0.2 \\
\hline Trehalose & $1.4 \pm 0.4$ & 0.3 & $1.2 \pm 0.4$ & 0.7 \\
\hline Arabitol & $3.7 \pm 0.5$ & 1.0 & $6.7 \pm 4.0$ & 2.0 \\
\hline Mannitol & $5.2 \pm 1.2$ & 0.9 & $6.3 \pm 3.4$ & 1.1 \\
\hline Nitrate $\left(\mu \mathrm{g} \mathrm{m}^{-3}\right)$ & $2.28 \pm 0.52$ & 0.72 & $2.16 \pm 0.63$ & 0.54 \\
\hline nss sulfate $\left(\mu \mathrm{g} \mathrm{m}^{-3}\right)$ & $1.51 \pm 0.53$ & 2.35 & $1.15 \pm 0.47$ & 0.38 \\
\hline Elemental carbon $\left(\mu \mathrm{g} \mathrm{C} \mathrm{m}^{-3}\right)$ & $0.13 \pm 0.23$ & 0.37 & $0.12 \pm 0.15$ & 0.29 \\
\hline Ambient temperature $\left({ }^{\circ} \mathrm{C}\right)$ & $22.9 \pm 1.7$ & $19.5 \pm 1.6$ & $22.3 \pm 2.2$ & $17.9 \pm 1.5$ \\
\hline Relative humidity (\%) & $79.4 \pm 7.3$ & $93.5 \pm 1.1$ & $74.4 \pm 10.1$ & $91.8 \pm 3.0$ \\
\hline
\end{tabular}

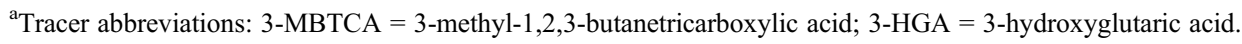

changes in temporal variations of these isoprene-SOA tracers during the two days. However, the concentrations of both 2-methylthreitol and 2-methylerthritol on D1 were much higher than those on D2 (Figure 6e). It is known that emission of isoprene is sensitive to temperature and solar radiation. The light intensity was much higher on D2, while the temperature range $\left(17-25^{\circ} \mathrm{C}\right)$ was similar on D1 and D2 (Figure 5a). Therefore it is unlikely that emission of isoprene was substantially higher on D1, although it was not measured in the present study. One possible explanation for the lower concentrations of the isoprene SOA tracers on D2 is that relatively more intense photochemical activity on D2 caused further oxidation of isoprene SOA on that day. It is likely that the increase in the WSOC/volume concentration ratios resulted partially from heterogeneous chemical reactions, adding isoprene oxidation products to the preexisting aerosol. Such an increase is also attributable to gas phase semi-VOC oxidation, followed by partitioning onto aerosol particles [Carlton et al., 2009]. The isoprene-SOA tracers may undergo particle phase accretion reactions, which can produce a wide range of high molecular weight species, such as oligomers (esters and hemiacetals) [Surratt et al., 2006; Szmigielski et al., 2007] and/or organosulfates [Surratt et al., 2008]. This hypothesis is partly supported by the higher WSOC concentrations and its ratio to particle volume concentration on D2 compared to D1.

[29] It is noteworthy that the non-sea-salt (nss) sulfate concentrations on 25 August $\left(1.51-2.35 \mu \mathrm{g} \mathrm{m}^{-3}\right)$ were higher than those on 26 August $\left(0.38-1.15 \mu \mathrm{g} \mathrm{m}^{-3}\right)$, indicating some anthropogenic influence on the observed aerosols. Recent studies suggest that the interaction of biogenic emissions with anthropogenic pollutants may increase SOA formation [e.g., Weber et al., 2007; Goldstein et al., 2009]. For example, increases in the SOA yields from acid-catalyzed reactions have been proposed in previous studies [e.g., Jang and Kamens, 2001; Surratt et al., 2006]. However, these acid-catalyzed reactions seem unlikely in this study because the observed aerosols were nearly neutralized or basic (data not shown). The relative importance of the anthropogenic influence on WSOC formation at this forest site is not clear from our data alone.

\subsubsection{Primary Biological Aerosol Particle Tracers in $\mathbf{P M}_{1.0}$}

[30] All the sugar compounds determined in this study (sucrose, trehalose, arabitol, and mannitol) are water soluble and can mostly be attributed to primary biological aerosol particles (PBAPs). Average concentrations of sucrose $(0.6 \pm$ $\left.0.5 \mathrm{ng} \mathrm{m}^{-3}\right)$ and trehalose $\left(1.1 \pm 0.5 \mathrm{ng} \mathrm{m}^{-3}\right)$ in $\mathrm{PM}_{1.0}$ were substantially lower than those in TSP (sucrose: $2.8 \pm$ $2.1 \mathrm{ng} \mathrm{m}^{-3}$; trehalose: $128.5 \pm 9.3 \mathrm{ng} \mathrm{m}^{-3}$ ) in the summer of 2010 [Miyazaki et al., 2012]. Similarly, concentrations of arabitol $\left(4.4 \pm 3.2 \mathrm{ng} \mathrm{m}^{-3}\right)$ and mannitol $\left(4.8 \pm 3.1 \mathrm{ng} \mathrm{m}^{-3}\right)$ in the submicrometer particles were much lower than those in TSP (arabitol: $129.4 \pm 63.3 \mathrm{ng} \mathrm{m}^{-3}$; mannitol: $232.3 \pm$ $152.5 \mathrm{ng} \mathrm{m}^{-3}$ ). These results indicate that the PBAPs mostly reside in the supermicrometer size range. This is in agreement with previous studies, which showed that sugar compounds are generally more abundant in the supermicrometer range than the submicrometer range, except for anhydrosugars [Fuzzi et al., 2007; Kourtchev et al., 2009; Pöschl et al., 2010; T. Zhang et al., 2010].

[31] All the PBAP tracers in the submicrometer particles exhibited clear diurnal variations, with peaks around noon (Figures $6 \mathrm{f}$ and $6 \mathrm{~g}$ ). The increased concentrations of sucrose and trehalose with increasing temperature indicate that biologically derived emissions (such as pollen or pollen fragment sources, resuspended soil dust and associated biota) are promoted during daytime. Previous studies have also reported higher daytime concentrations of sucrose in larger particles at forest sites [Graham et al., 2003; Ion et al., 2005; Fu 
and Kawamura, 2011]. These studies attributed the higher concentrations to specific daytime release of large fungal spores, fern spores, pollen grains, and plant fragments. Arabitol and mannitol are common polyols present in many green algal lichens [Lewis and Smith, 1967; Dahlman et al., 2003] and are constituents of fungi and bacteria [Bieleski, 1982]. The elevated concentrations of arabitol and mannitol during daytime were also reported for $\mathrm{PM}_{2.5}$ at a rural site in Hungary [Ion et al., 2005]. However, the higher daytime concentrations contrast with previous studies made for the coarse particle (with aerodynamic diameter $>2.5 \mu \mathrm{m}$ ) in the Amazon forest [Graham et al., 2003; Claeys et al., 2010] where the concentrations of arabitol and mannitol were higher at night. One possible explanation for this difference is that emission of smaller-sized fungal fragments is more pronounced in temperate/boreal forests, whereas hygroscopic growth of particles containing arabitol and mannitol in tropical forests may shift the particle size to a coarse-mode size range at night [Ion et al., 2005]. It should be noted that concentrations of arabitol $\left(6.7 \pm 4.0 \mathrm{ng} \mathrm{m}^{-3}\right)$ and mannitol $\left(6.3 \pm 3.4 \mathrm{ng} \mathrm{m}^{-3}\right)$ on D2 were much higher than those on D1 (Figure 6g). This result indicates that emissions of these compounds are associated with light intensity as well as ambient temperature. In summary, the diurnal variations of the PBAP tracers in this study suggest solar radiation and temperature-induced emissions of submicrometer PBAP at the forest site.

[32] We also found that nitrate in the submicrometer particles exhibited a clear diurnal variation similar to the PBAPs, peaking around noontime (Figure $6 \mathrm{~h}$ ). The main possible source of nitrate observed at this site was likely the oxidation of anthropogenic $\mathrm{NO}_{x}$ and/or oxidation of soilderived $\mathrm{NO}_{x}$ from the forest floor [e.g., Su et al., 2011]. In general, the EC concentrations were low during the day $\left(0.13 \pm 0.20 \mu \mathrm{g} \mathrm{C} \mathrm{m}^{-3}\right)$, when nitrate concentrations were elevated, particularly on D2 (Figure 6h). Meanwhile, nitrate was positively correlated with trehalose $\left(r^{2}=0.76\right)$ in the submicrometer particles. Together, these results imply that emissions from the forest floor contribute significantly to the PBAP and nitrate concentrations. This implication is supported by our previous study [Miyazaki et al., 2012], which inferred that the forest floor, including ground vegetation and soil, acts as a significant source of WSOC in TSP on the basis of vertical profiles of WSOC and biogenic tracers in the forest canopy.

\subsubsection{Contributions of BSOA and PBAP to Submicrometer WSOC}

[33] Based on PMF analyses, Miyazaki et al. [2012] estimated that biogenic SOA production $(\sim 50 \%$ from $\alpha$ - and $\beta$-pinene SOA and $\sim 40 \%$ from isoprene SOA) accounted for $\sim 90 \%$ of WSOC in TSP in July and August 2010 at the same forest site. The concentrations of $\alpha$ - and $\beta$-pinene SOA and isoprene SOA tracers in the submicrometer particles in this study are similar to those in TSP. This supports that SOA formation is tightly linked to the production of submicrometer WSOC in the forest atmosphere. In contrast, our PMF analyses indicated that PBAPs accounted for only $<5 \%$ of WSOC even in TSP [Miyazaki et al., 2012]. Additionally, an increase in aerosol mass dominated by primary emissions would not result in an apparent growth of the particles as shown in Figures 1c and $6 \mathrm{~b}$. These results suggest that PBAPs are responsible only for a small fraction of WSOC in the submicrometer particles. In combination, the estimated fraction of BSOA discussed above presents a lower limit for the production of submicrometer WSOC in the current study.

[34] Interestingly, the concentrations of 3-HGA and isoprene SOA tracers increased during the night (Figures $6 \mathrm{~d}$ and 6e). It is likely that such increases may have resulted at least partially from different and/or additional oxidation processes (not explicitly dependent on temperature) at night. Higher relative humidity (>90\%) at night (Table 1) may contribute to the particle growth of water-soluble organic aerosols and aerosol water content which promotes aqueous phase production of WSOC [e.g., Hennigan et al., 2008; Ervens et al., 2011] to some extent. Although WSOC and its ratio to particle volume did not exhibit a significant increase at night (Figure 6a), these nighttime oxidation processes may possibly contribute to the WSOC formation.

\subsubsection{Temperature Dependence of Biogenic SOA and Association With WSOC}

[35] As shown in Figure 4, the WSOC concentrations increase with ambient temperature during the day. $Y$. $Y$. Zhang et al. [2010] recently found an Arrhenius-type correlation between the 3-MBTCA concentration and inverse temperature with a temperature range of $275-300 \mathrm{~K}$ based on weekly ambient aerosol samples collected in Mainz, Germany. They suggested that the temperature dependence of 3-MBTCA is largely due to enhanced photochemical production by hydroxyl radicals $(\mathrm{OH})$, indicating that 3-MBTCA can be used as a tracer for chemical aging of BSOA by $\mathrm{OH}$. Considering that 3-MBTCA is formed by $\mathrm{OH}$-initiated oxidation of cis-pinonic acid (PA) [Szmigielski et al., 2007; Müller et al., 2012], a ratio of 3-MBTCA to PA concentrations can be used as an indicator of photochemical aging of BSOA. Indeed, the temporal variation of the 3-MBTCA/PA ratios followed that of $\mathrm{O}_{3}$, as shown in Figure 5b, supporting this hypothesis.

[36] Here we examine the temperature dependencies for $\alpha$ - and $\beta$-pinene SOA tracers on a timescale of a few hours to $12 \mathrm{~h}$, corresponding to that of the aerosol sampling periods. Figure 7 presents Arrhenius-type temperature dependencies for concentrations of 3-MBTCA and pinonic acid in the submicrometer ranges as a function of the inverse temperature $(1 / T)$. The 3-MBTCA concentrations exhibited a strong temperature dependence during daytime with a $\mathrm{r}^{2}$ of 0.85 (Figure 7a). On the other hand, the temperature dependence of PA during daytime is weak $\left(\mathrm{r}^{2}=0.16\right.$; Figure $\left.7 \mathrm{~b}\right)$, which is in agreement with previous studies [Y. Y. Zhang et al., 2010; Gómez-González et al., 2012]. A cancelation of the temperature dependencies of the PA formation from pinene and the loss of PA by further $\mathrm{OH}$ oxidation could explain the poor correlation between the PA concentrations and temperature. The activation energy (Ea) for 3-MBTCA (daytime) in our data was calculated to be $123 \pm 11 \mathrm{~kJ} \mathrm{~mol}^{-1}$ from the slope of the scatterplot (Figure 7a) [Y. Y. Zhang et al., 2010]. This value is close to that $\left(126 \pm 10 \mathrm{~kJ} \mathrm{~mol}^{-1}\right)$ observed for 3MBTCA in the weekly aerosol samples collected in Mainz, Germany [Y. Y. Zhang et al., 2010], indicating that the $\mathrm{OH}-$ initiated oxidation of PA limits the formation of 3-MBTCA and explains the temperature dependence.

[37] Figure 8 presents the WSOC/volume concentration ratios as a function of 3-MBTCA/PA ratios. Clearly, the WSOC/volume concentration ratios increase from 0.45 to $1.06 \mu \mathrm{g} \mathrm{C} \mathrm{m}^{-3} /\left(\mu \mathrm{m}^{3} \mathrm{~cm}^{-3}\right)$ with the 3-MBTCA/PA ratios 
(a)

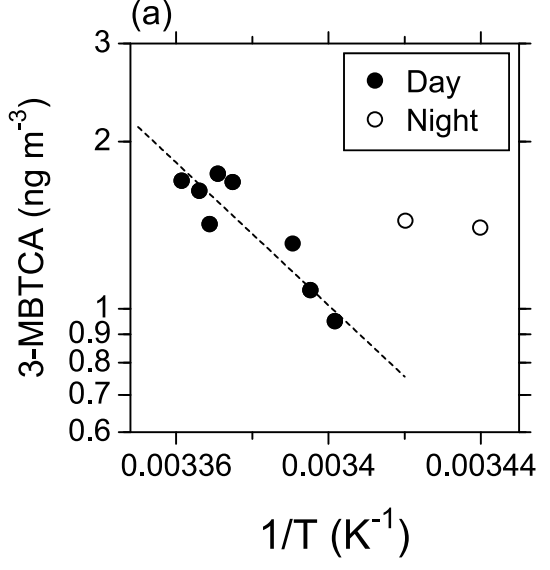

(b)

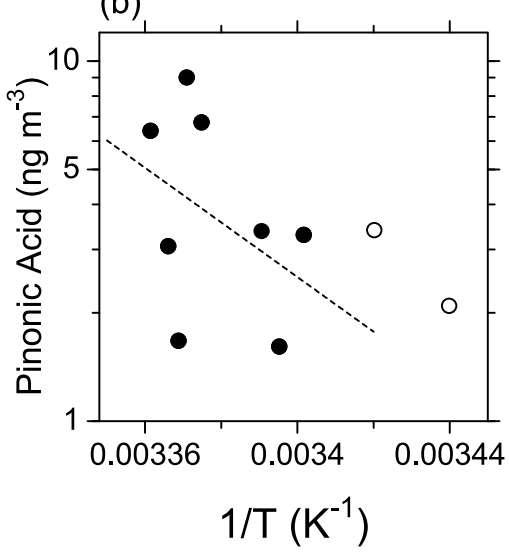

Figure 7. Arrhenius-type temperature dependencies observed for pinene oxidation products: mass concentrations of (a) 3-MBTCA and (b) pinonic acid in submicrometer size ranges as a function of inverse temperature $(1 / \mathrm{T})$. Solid circles indicate daytime data, and open circles indicate the nighttime data during the period of 25-27 August 2010.

during daytime, while a relation does not exist in nighttime. Although the number of samples is limited, this result indicates that a major fraction of WSOC in the submicrometer size range observed at this forest site is associated with $\mathrm{OH}$ initiated photochemical aging of BSOA during daytime. This finding also supports there being minor contribution of PBAPs to WSOC mass during the study period, as discussed previously. To summarize, this work provides clear evidence of WSOC formation at the deciduous forest site during daytime and emphasizes the importance of particle growth of biogenic WSOC which strongly depends on temperature and solar radiation.

\section{Conclusions}

[38] We conducted time-resolved measurements of watersoluble organics and particle size distributions in submicrometer aerosols using online methods and filter samplings at a deciduous forest site in northern Japan in summer. New particle formation and subsequent growth of the particles were frequently observed, which were typically accompanied by an increase in WSOC mass concentrations during daytime. We also found that daily averaged WSOC concentrations increased with increasing gross primary production of $\mathrm{CO}_{2}$ by the forest ecosystem. Moreover, the WSOC concentration increased with increasing ambient temperature during daytime. These results provide evidence that formation of submicrometer WSOC in summer is closely linked to photosynthetic activity by the forest, which is dependent on ambient temperature and light intensity.

[39] Off-line chemical analysis together with particle size distributions in a 2 day event of elevated WSOC concentrations suggests that photochemical aging of both $\alpha$ - and $\beta$-pinene and isoprene oxidation products contribute to the particle growth and the subsequent increase in WSOC around noontime. The diurnal variations in PBAP tracers, which showed distinct peaks around noontime, also indicated both light intensity and temperature-induced emissions of submicrometer PBAP at the forest site. However, the particle growth data together with comparison to our TSP measurements indicates that the contribution of PBAP to the submicrometer WSOC mass appeared to be insignificant.

[40] An Arrhenius-type correlation was observed between 3-MBTCA concentrations and inverse temperature during the day $\left(r^{2}=0.85\right)$, whereas the correlation was not apparent at night. For the daytime data, the ratios of WSOC to particle volume concentrations were positively correlated with the concentration ratios of 3-MBTCA to pinonic acid. These results indicate that particle growth of biogenic WSOC was controlled by ambient temperature as well as solar radiation during the day. The result also supports that the ratios of 3-MBTCA to pinonic acid in submicrometer particles can be used as a tracer for chemical aging of biogenic SOA from deciduous forest vegetation. The current study provides evidence of a dominant biogenic contribution to secondary formation of submicrometer WSOC in the deciduous forest ecosystem. The finding could be significant because these

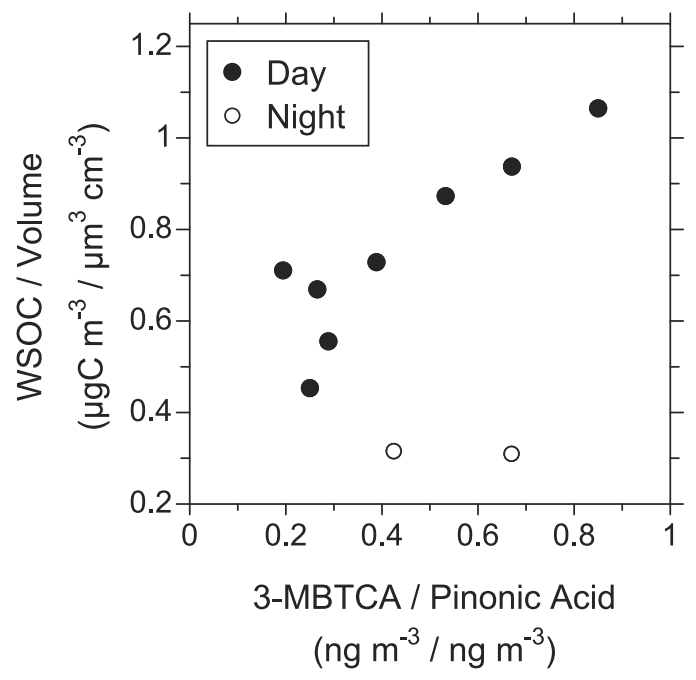

Figure 8. Ratios of WSOC to particle volume concentrations as a function of 3-MBTCA/pinonic acid concentration ratios for daytime (solid circles) and nighttime (open circles) from 25 to 27 August 2010. 
small WSOC particles have potential to impact on biologically regulated $\mathrm{CCN}$ population and thus radiation budget and carbon cycles in the forest region.

[41] Acknowledgments. This research was supported in part by grants-in-aid for scientific research from the Ministry of Education, Culture, Sports, Science and Technology (MEXT), Japan. This research was also supported by the Environment Research and Technology Development Fund (B-0903) of the Ministry of the Environment, Japan. The authors thank G. Engling for his helpful comments on the manuscript.

\section{References}

Atkinson, R., et al. (2006), Evaluated kinetic and photochemical data for atmospheric chemistry: Volume II-Gas phase reactions of organic species, Atmos. Chem. Phys., 6, 3625-4055, doi:10.5194/acp-6-3625-2006.

Bieleski, R. L. (1982), Sugar alcohols, in Encyclopedia of Plant Physiology, vol. 13A, Plant Carbohydrates, Intracellular Carbohydrates, vol. I edited by A. Loewis and W. Tanner, pp. 158-170, Springer, Berlin.

Birch, M. E., and R. A. Cary (1996), Elemental carbon-based method for monitoring occupational exposures to particulate diesel exhaust, Aerosol Sci. Technol., 25, 221-241, doi:10.1080/02786829608965393.

Bonan, G. (2008), Forests and climate change: Forcings, feedbacks, and the climate benefits of forests, Science, 320, 1444-1449, doi:10.1126/ science. 1155121.

Carlton, A. G., C. Wiedinmyer, and J. H. Kroll (2009), A review of secondary organic aerosol (SOA) formation from isoprene, Atmos. Chem. Phys, 9, 4987-5005, doi:10.5194/acp-9-4987-2009.

Cavalli, F., M. C. Facchini, S. Decesari, L. Emblico, M. Mircea, N. R. Jensen, and S. Fuzzi (2006), Size-segregated aerosol chemical composition at a boreal site in southern Finland, during the QUEST project, Atmos. Chem. Phys., 6, 993-1002, doi:10.5194/acp-6-993-2006.

Claeys, M., et al. (2004), Formation of secondary organic aerosols through photooxidation of isoprene, Science, 303, 1173-1176, doi:10.1126/ science. 1092805.

Claeys, M., et al. (2007), Hydroxydicarboxylic acids: Novel markers for secondary organic aerosol from the photooxidation of $\alpha$-pinene, Environ. Sci. Technol., 41, 1628-1634, doi:10.1021/es0620181.

Claeys, M., et al. (2009), Terpenylic acid and related compounds from the oxidation of alpha-pinene: Implications for new particle formation and growth above forest, Environ. Sci. Technol., 43, 6976-6982, doi:10.1021/es9007596.

Claeys, M., et al. (2010), Polar organic marker compounds in atmospheric aerosols during the LBA-SMOCC 2002 biomass burning experiment in Rondônia, Brazil: Sources and source processes, time series, diel variations and size distributions, Atmos. Chem. Phys., 10, 9319-9331, doi:10.5194/acp-10-9319-2010.

Dahlman, L., J. Persson, T. Näsholm, and K. Palmqvist (2003), Carbon and nitrogen distribution in the green algal lichens Hypogymnia physodes and Platismatia glauca in relation to nutrient supply, Planta, 217, 41-48.

De Gouw, J., and J. L. Jimenez (2009), Organic aerosols in the Earth's atmosphere, Environ. Sci. Technol., 43, 7614-7618, doi:10.1021/ es9006004.

Duong, H. T., et al. (2011), Water-soluble organic aerosol in the Los Angeles Basin and outflow regions: Airborne and ground measurements during the 2010 CalNex field campaign, J. Geophys. Res., 116, D00V04, doi:10.1029/2011JD016674.

Elbert, W., P. E. Taylor, M. O. Andreae, and U. Pöschl (2007), Contribution of fungi to primary biogenic aerosols in the atmosphere: Wet and dry discharged spores, carbohydrates, and inorganic ions, Atmos. Chem. Phys., 7, 4569-4588, doi:10.5194/acp-7-4569-2007.

Ervens, B., B. J. Turpin, and R. J. Weber (2011), Secondary organic aerosol formation in cloud droplets and aqueous particles (aqSOA): A review of laboratory, field and model studies, Atmos. Chem. Phys., 11, 11,069-11,102, doi:10.5194/acp-11-11069-2011.

$\mathrm{Fu}, \mathrm{P}$., and K. Kawamura (2011), Diurnal variations of polar organic tracers in summer forest aerosols: A case study of a Quercus and Picea mixed forest in Hokkaido, Japan, Geochem. J., 45, 297-308.

Fu, P., K. Kawamura, J. Chen, and L. Barrie (2009), Isoprene, monoterpene, and sesquiterpene oxidation products in the high Arctic aerosols during late winter to early summer, Environ. Sci. Technol., 43, 4022-4028, doi:10.1021/es803669a.

Fuzzi, S., et al. (2007), Overview of the inorganic and organic composition of size-segregated aerosol in Rondônia, Brazil, from the biomass-burning period to the onset of the wet season, J. Geophys. Res., 112, D01201, doi:10.1029/2005JD006741.
Goldstein, A. H., C. D. Koven, C. L. Heald, and I. Y. Fung (2009), Biogenic carbon and anthropogenic pollutants combine to form a cooling haze over the southeastern United States, Proc. Natl. Acad. Sci. U. S. A., 106, 8835-8840, doi:10.1073/pnas.0904128106.

Gómez-González, Y., W. Wang, R. Vermeylen, X. Chi, J. Neirynck, I. A. Janssens, W. Maenhaut, and M. Claeys (2012), Chemical characterization of atmospheric aerosols during a 2007 summer field campaign at Brasschaat, Belgium: Sources and source processes of biogenic secondary organic aerosol, Atmos. Chem. Phys., 12, 125-138, doi:10.5194/ acp-12-125-2012.

Graham, B., et al. (2003), Organic compounds present in the natural Amazonian aerosol: Characterization by gas chromatography-mass spectrometry, J. Geophys. Res., 108(D24), 4766, doi:10.1029/2003JD003990.

Hallquist, M., et al. (2009), The formation, properties and impact of secondary organic aerosol: Current and emerging issues, Atmos. Chem. Phys., 9, 5155-5236, doi:10.5194/acp-9-5155-2009.

Hennigan, C. J., M. H. Bergin, J. E. Dibb, and R. J. Weber (2008), Enhanced secondary organic aerosol formation due to water uptake by fine particles, Geophys. Res. Lett., 35, L18801, doi:10.1029/ 2008GL035046.

Holzinger, R., A. Lee, K. T. Paw, and A. H. Goldstein (2005), Observations of oxidation products above a forest imply biogenic emissions of very reactive compounds, Atmos. Chem. Phys., 5, 67-75, doi:10.5194/acp-567-2005.

Ion, A. C., R. Vermeylen, I. Kourtchev, J. Cafmeyer, X. Chi, A. Gelencsér, W. Maenhaut, and M. Claeys (2005), Polar organic compounds in rural $\mathrm{PM}_{2.5}$ aerosols from K-puszta, Hungary, during a 2003 summer field campaign: Sources and diel variations, Atmos. Chem. Phys., 5, 1805-1814, doi:10.5194/acp-5-1805-2005.

Jang, M., and R. M. Kamens (2001), Atmospheric secondary aerosol formation by heterogeneous reactions of aldehydes in the presence of a sulfuric acid aerosol catalyst, Environ. Sci. Technol., 35, 4758-4766, doi:10.1021/ es010790s.

Kavouras, I. G., N. Mihalopoulos, and E. G. Stephanou (1998), Formation of atmospheric particles from organic acids produced by forests, Nature, 395, 683-686, doi:10.1038/27179.

Kitamura, K., Y. Nakai, S. Suzuki, Y. Ohtani, K. Yamanoi, and T. Sakamoto (2012), Interannual variability of net ecosystem production for a broadleaf deciduous forest in Sapporo, northern Japan, J. For. Res., 17, 323-332, doi:10.1007/s10310-012-0335-4.

Kourtchev, I., et al. (2008), Determination of isoprene and $\alpha-/ \beta$-pinene oxidation products in boreal forest aerosols from Hyytiälä, Finland: Diel variations and possible link with particle formation events, Plant Biol., 10, 138-149, doi:10.1055/s-2007-964945.

Kourtchev, I., L. Copolovici, M. Claeys, and W. Maenhaut (2009), Characterization of atmospheric aerosols at a forested site in central Europe, Environ. Sci. Technol., 43, 4665-4671, doi:10.1021/es803055w.

Kulmala, M., et al. (2004), A new feedback mechanism linking forests, aerosols, and climate, Atmos. Chem. Phys., 4, 557-562, doi:10.5194/ acp-4-557-2004

Leaitch, W. R., et al. (2011), Temperature response of the submicron organic aerosol from temperate forests, Atmos. Environ., 45, 6696-6704, doi:10.1016/j.atmosenv.2011.08.047.

Lewis, D. H., and D. C. Smith (1967), Sugar alcohols (polyols) in fungi and green plants: 1. Distribution, physiology and metabolism, New Phytol. 66, 143-184, doi:10.1111/j.1469-8137.1967.tb05997.x.

Mahowald, N. (2011), Aerosol indirect effect on biogeochemical cycles and climate, Science, 334, 794-796, doi:10.1126/science.1207374.

Mäkelä, J. M., et al. (2001), Chemical composition of aerosol during particle formation events in boreal forest, Tellus, Ser. B, 53, 380-393.

Miyazaki, Y., et al. (2006), Time-resolved measurements of water-soluble organic carbon in Tokyo, J. Geophys. Res., 111, D23206, doi:10.1029/ 2006JD007125.

Miyazaki, Y., K. Kawamura, J. Jung, H. Furutani, and M. Uematsu (2011), Latitudinal distributions of organic nitrogen and organic carbon in marine aerosols over the western North Pacific, Atmos. Chem. Phys., 11, $3037-$ 3049, doi:10.5194/acp-11-3037-2011

Miyazaki, Y., P. Q. Fu, K. Kawamura, Y. Mizoguchi, and K. Yamanoi (2012), Seasonal variations of stable carbon isotopic composition and biogenic tracer compounds of water-soluble organic aerosols in a deciduous forest, Atmos. Chem. Phys., 12, 1367-1376, doi:10.5194/acp-121367-2012.

Müller, L., M.-C. Reinnig, K. H. Naumann, H. Saathoff, T. F. Mentel, N. M. Donahue, and T. Hoffmann (2012), Formation of 3-methyl-1,2,3butanetricarboxylic acid via gas phase oxidation of pinonic acid-A mass spectrometric study of SOA aging, Atmos. Chem. Phys., 12, 1483-1496, doi:10.5194/acp-12-1483-2012. 
Nakai, Y., K. Kitamura, S. Suzuki, and S. Abe (2003), Year-long carbon dioxide exchange above a broadleaf deciduous forest in Sapporo, northern Japan, Tellus, Ser. B, 55, 305-312.

Peltier, R. E., et al. (2007), Fine aerosol bulk composition measured on WP$3 \mathrm{D}$ research aircraft in vicinity of the northeastern United States-Results from NEAQS, Atmos. Chem. Phys., 7, 3231-3247, doi:10.5194/acp-73231-2007.

Peñuelas, J., and M. Staudt (2010), BVOCs and global change, Trends Plant Sci., 15, 133-144, doi:10.1016/j.tplants.2009.12.005.

Pöschl, U., et al. (2010), Rainforest aerosols as biogenic nuclei of clouds and precipitation in the Amazon, Science, 329, 1513-1516, doi:10.1126/ science. 1191056.

Simoneit, B. R. T., et al. (2004), Sugars-dominant water-soluble organic compound in soils and characterization as tracers in atmospheric particulate matter, Environ. Sci. Technol., 38, 5939-5949, doi:10.1021/ es0403099.

$\mathrm{Su}, \mathrm{H}$., et al. (2011), Soil nitrite as a source of atmospheric HONO and $\mathrm{OH}$ radicals, Science, 333, 1616-1618, doi:10.1126/science.1207687.

Sullivan, A. P., R. J. Weber, A. L. Clements, J. R. Turner, M. S. Bae, and J. J. Schauer (2004), A method for on-line measurement of water-soluble organic carbon in ambient aerosol particles: Results from an urban site, Geophys. Res. Lett., 31, L13105, doi:10.1029/2004GL019681.

Sullivan, A. P., et al. (2006), Airborne measurements of carbonaceous aerosol soluble in water over northeastern United States: Method development and an investigation into water-soluble organic carbon sources, J. Geophys. Res., 111, D23S46, doi:10.1029/2006JD007072.

Surratt, J. D., et al. (2006), Chemical composition of secondary organic aerosol formed from the photooxidation of isoprene, J. Phys. Chem. A 110, 9665-9690, doi:10.1021/jp061734m.

Surratt, J. D., et al. (2008), Organosulfate formation in biogenic secondary organic aerosol, J. Phys. Chem. A, 112, 8345-8378, doi:10.1021/ jp802310p.
Szmigielski, R., et al. (2007), 3-methyl-1,2,3-butanetricarboxylic acid: An atmospheric tracer for terpene secondary organic aerosol, Geophys. Res. Lett., 34, L24811, doi:10.1029/2007GL031338.

Tunved, P , H.C. Hansson, V.-M. Kerminen, J. Ström, M. Dal Maso, H. Lihavainen, Y. Viisanen, P. P. Aalto, M. Komppula, and M. Kulmala (2006), High natural aerosol loading over boreal forests, Science, 312, 261-263, doi:10.1126/science.1123052.

Weber, R. J., et al. (2007), A study of secondary organic aerosol formation in the anthropogenic-influenced southeastern United States, J. Geophys. Res., 112, D13302, doi:10.1029/2007JD008408.

Wofsy, S. C., M. L. Goulden, J. W. Munger, S.-M. Fan, P. S. Bakwin, B. C Daube, S. L. Bassow, and F. A. Bazzaz (1993), Net exchange of $\mathrm{CO}_{2}$ in mid-latitude forest, Science, 260, 1314-1317, doi:10.1126/science.260. 5112.1314.

Wong, J. P. S., A. K. Y. Lee, J. G. Slowik, D. J. Cziczo, W. R. Leaitch, A. Macdonald, and J. P. D. Abbatt (2011), Oxidation of ambient biogenic secondary organic aerosol by hydroxyl radicals: Effects on cloud condensation nuclei activity, Geophys. Res. Lett., 38, L22805, doi:10.1029/ 2011GL049351.

Yu, J., D. R. Cocker III, R. J. Griffin, R. C. Flagan, and J. H. Seinfeld (1999), Gas phase ozone oxidation of monoterpenes: Gaseous and particulate products, J. Atmos. Chem., 34, 207-258, doi:10.1023/A:1006254930583.

Zhang, T., et al. (2010), Contribution of fungal spores to particulate matter in a tropical rainforest, Environ. Res. Lett., 5, 024010, doi:10.1088/17489326/5/2/024010.

Zhang, Y. Y., L. Müller, R. Winterhalter, G. K. Moortgat, T. Hoffmann, and U. Pöschl (2010), Seasonal cycle and temperature dependence of pinene oxidation products, dicarboxylic acids and nitrophenols in fine and coarse air particulate matter, Atmos. Chem. Phys., 10, 7859-7873, doi:10.5194/acp-10-7859-2010. 